\title{
Nursing degree "opens doors beyond bags, beds and bedpans"
}

Published at www.cmaj.ca on Dec. 22, 2009

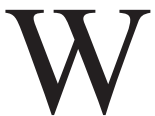
hile England ponders the consequences of its recent move to make nursing a university-degree profession by 2013 , the impact of Canada's decade-long foray into elevated nursing credentials remains unclear.

English unions, health care professionals and patients alike have lately voiced fears that upgrading entry credentials will lead to less hands-on training, shortages in the nursing supply and a general attitude of being "too posh to wash" among academic nurses ill-prepared for the menial tasks required in the direct provision of health care.

But if the English want to know what's in store 10 years down the road, Canada has little to offer in the way of an answer, as there is no consensus and even less concrete evidence to muster on behalf of either side of the argument.

While Canadian advocates of the change say degree nurses are better prepared for the challenges of an increasingly complex health care system, critics worry that phasing out diploma programs entirely may have exacerbated the nation's shortage of registered nurses.

New Brunswick has never regretted its 1998 decision to become one of the first provinces in Canada to require a baccalaureate degree to practise nursing, says Margaret Dykeman, professor of nursing at the University of New Brunswick in Fredericton.

"Let's not romanticize what the diploma program did. Bottom line, we ran a hospital and got a half-decent education while doing it, but it was more luck and practice than knowledge," says Dykeman, who originally trained for a nursing diploma before returning to school to pursue a doctorate. "The primary onus for the student should be to learn, not to fill the gap when a hospital isn't adequately staffed."

According to the Canadian Nurses Association website, "the knowledge,

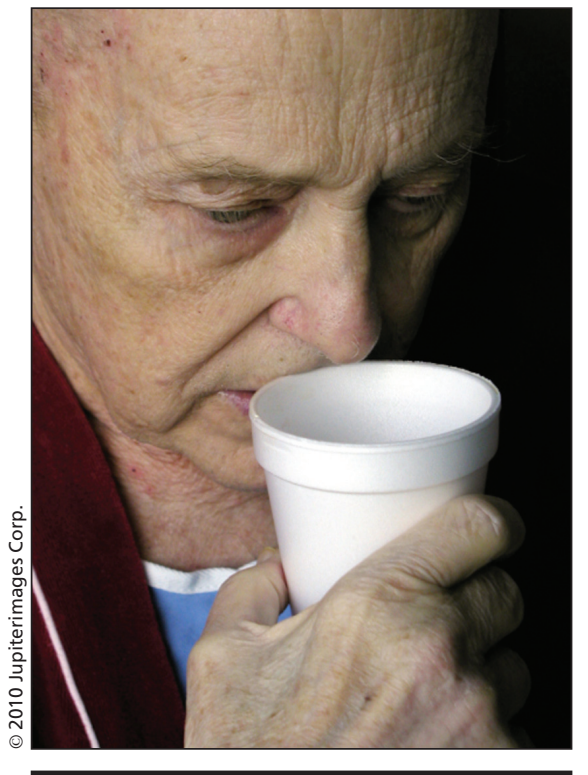

As of 2010, nursing will be an all-graduate profession in Canada; but as the consequences of the decade-long transition remain unmeasured and unknown, critics fear the change may have worsened standards of quality and safety in the nation's health care system.

skills and personal attributes that today's health system demands of its registered nurses can only be gained through broad-based baccalaureate nursing programs." It also cites a study that indicates there was a $5 \%$ decrease in risk of patient death for every $10 \%$ increase in the proportion of hospital registered nurses holding degrees (JAMA 2003;290[12]:1617-23).

"My diploma course never talked about outcomes, the patient just got better or died," says Dykeman. "Today, we have to prepare students to think critically, tackle higher workloads, deal with advanced procedures and technologies, push policy and advocate for the patient, in addition to the basic bedside care we were trained for in the past."

But Steven Lewis, a policy expert for the federal-provincial-territorial Coordinating Committee on Entry to Practice Credentials, says that beyond anecdotal evidence, no Canadian research has proven that the previous credential system was "substandard" or harmful to the public.

"Government never instigated the upgrades and employers certainly never demanded the change, although they've often opposed it," Lewis explains. "When employers see credential requirements increasing, they see the time it takes to educate nurses increasing, meaning potential shortages in the workforce. They see pressure for increased pay as a result of those shortages and they see a mismatch between the expectation of nurses leaving school and the actual work they'll be doing."

Lewis also points out that university degree programs provide a broader but not necessarily deeper education. "The highly focused 23-month diploma process has been replaced by the more general four-year program, but because universities weren't producing enough nurses to meet demand, there's also a plethora of fast-track options. It's peculiar to say we can produce a competent entry level nurse by tacking two years of training on top of a fine arts degree, when apparently we couldn't achieve the same results with a more practical two-year diploma program in the past."

The attraction of "having schooling that was in line with other health professionals," though, was a major factor in the push for raising credentials, according to the Canadian Nurses Association website.

"If we' re expected to work as part of a multidiscipline team to provide the best patient care possible, how can we be credible when everyone has a degree except the nurse?" Dykeman explains.

Yet, Lewis says. making all nurses university educated won't level the playing field. "If the majority of nurses have degrees today, that's no different from the majority of nurses having diplomas 25 years ago; if everyone has a degree, it's as if no one has a degree. 
Nurses are still being defined by what they do, and differences in how they were educated come out in the wash once they're actually in the workplace."

Canadian Institute of Health Information data indicates that $86.5 \%$ of Canada's registered nurses with a degree were still working in direct care as of 2006 (http://secure.cihi.ca/cihi web/dispPage.jsp?cw_page=statistics _nursing_2006_e). That suggests the roles of nurses haven't significantly changed, despite the new credentials requirement.

"In the 1980s, my physician told me I had to get out of nursing, and I remember someone telling me, 'You can't do anything else, you're a nurse'," says Dykeman. "The difference a degree makes is that it opens doors beyond bags, beds and bedpans."

However, Lewis worries that as a degree opens doors for some nurses, it may close them for others. "By requiring a baccalaureate, right off the bat you exclude people from lower income brackets, but you also see a double barrel effect because the ongoing cost and stressors of a degree program not only prevent some people from entering but also weed out others along the way."

Audrey Lawrence of the Aboriginal Nurses Association of Canada agrees that the extended time it takes to obtain a degree has posed a barrier for Aboriginal people interested in nursing, many of whom have families and other financial responsibilities when they enter postsecondary education. Lawrence says many Aboriginal students are required to complete their training on a part-time basis, extending the cost of their study period beyond the four years covered by government funding.

Health Canada says the top two reasons students drop out of nursing programs are the financial and academic burdens associated with a degree program (www.hc-sc.gc.ca/hcs-sss /pubs/nurs-infirm/onp-bpsi-fs-if/2006 -educ-eng.php).

As of 2010, all Canadian provinces and territories will have made the switch to requiring a baccalaureate degree for entry to practise as a registered nurse, excluding Quebec, which continues to offer diploma programs, and the Yukon, which permits no entrylevel education in nursing (www.cna -nurses.ca/CNA/nursing/education/bacca laureate/table/default_e.aspx).

The piecemeal nature of the change over the past decade has ultimately made it difficult to track, says Lewis. "This transition wasn't made as thoughtfully as it could have been, and it would be nice to have some real information and data to refer to so we don't have to be locked in a purely speculative argument of its impact," he adds. "Because it's not stopping at an undergrad and if we don't look into it now, we may well see doctoral level entry into nursing one day."

The Canadian Nurses Association projects that the shortage of nurses who provide direct clinical care will climb to the equivalent of almost 60000 fulltime nurses by 2022 (www.cna-aiic .ca/CNA/news/releases/public_release _e.aspx?id=249). — Lauren Vogel, Ottawa, Ont.

DOI:10.1503/cmaj.109-3143 